\title{
СОВРЕМЕННЫЕ МЕТОДИЧЕСКИЕ ТЕХНОЛОГИИ НА ПРАКТИЧЕСКИХ ЗАНЯТИЯХ ПО РКИ В ЛИТОВСКОЙ ВОЕННОЙ АКАДЕМИИ
}

\author{
Доц. др. Елена Казимянец \\ Литовская военная академия им. генерала Йонаса Жямайтиса
}

\begin{abstract}
Аннотация. Статья посвящеена анализу задач и специфики обучения русскому языку в качестве второго иностранного языка в Литовской военной академии. В статье определяется набор качеств, составляющих профессиональную речевую и лингвистическую компетентность выпускника высшего военного учебного заведения. Автор подчёркивает важность создания у обучаемых необходимого для профессионального общения с представителями различных языковых групп словаря на иностранном (русском) языке. В работе указывается цуелесообразность ввода специильной военной лексики и терминологии с самых ранних этапов обучения иностранному языку. B статье также обосновывается необходимость интенсификации учебного процесса за счёт использования новейших методов и технологий обучения иностранным языкам, органичного сочетания разных методов обучения в рамках одного занятия и рассматривается метод активизации как один из основных методов обучения русскому языку в Литовской военной академии.
\end{abstract}

Ключевые слова: РКИ, технологии обучения, метод активизачии, профессиональная речевая компетентность военного специалиста.

\section{Введение}

Военное образование находится в ряду важнейших факторов обеспечения национальной безопасности любой страны, в частности Литовской Республики. Важным аспектом профессиональной подготовки современного военного специалиста является хорошее владение иностранными языками. Принимая во внимание языковую политику ЕC, направленную на многоязычие современного общества, можно утверждать, что изучение, помимо английского, второго иностранного языка (в том числе русского) приобретает важнейшее значение. Таким образом, перед преподавателем РКИ ставится сложнейшая задача: в довольно сжатом - в плане учебных часов - курсе обеспечить учащихся знанием не только минимума общеупотребительных в формальном и неформальном общении слов и необходимых для продуцирования 
речи правил грамматики, но также знанием профессиональной военной лексики. Такая постановка проблемы требует от методиста-преподавателя максимальной интенсификации учебного процесса, поиска новых методов и подходов к обучению, отвечающих как поставленной задаче, так и современному состоянию методической науки, и кроме того, продуманного и адекватного ситуации сочетания разных методов обучения в ходе занятий. Ибо что такое технология обучения? В сущности, как правильно отмечает А.К. Колеченко в работе «Энциклопедия педагогических технологий», «это набор операций по конструированию, формированию и контролю знаний, умений, навыков и отношений в соответствии с поставленными целями» (цит. по Шантурова, 2013: 28). Это определенная инструкция для преподавателя - что и как надо делать. Что - определяется учебной программой и является стандартом. Как - это то, что выбирается преподавателем, совершенствует его мастерство и дает ему поле для творчества.

Целью нашего исследования является анализ факторов, методов и приёмов, обеспечивающих наиболее оптимальное усвоение необходимого языкового материала на занятиях по РКИ (в Литовской военной академии).

В ходе исследования решаются следующие задачи:

- определяются приоритеты отбора и ввода учебного языкового материала в условиях обучения в военном вузе и исключительная важность интенсификации лексической работы на занятиях по РКИ;

- определяются приоритеты отбора и ввода учебного языкового материала в условиях обучения в военном вузе и исключительная важность интенсификации лексической работы на занятиях по РКИ;

- устанавливается набор качеств, составляющих профессиональную речевую и лингвистическую компетентность выпускника высшего военного учебного заведения;

- характеризуется специфика методической работы в преподавании второго иностранного языка в военном учебном заведении;

- разрабатываются пути интенсификации учебного процесса при обучении РКИ;

- рассматриваются целесообразность и преимущества использования метода активизации на занятиях по РКИ;

- анализируются основные принципы, лежащие в основе метода активизации, в приложении к академическому курсу русского языка в Литовской военной академии. 


\section{Основная часть}

В современных условиях, когда литовским военным специалистам приходится иметь дело с вооружением разных стран и в ходе службы контактировать с военнослужащими других государств и национальностей, языковая подготовка военного профессионала приобретает исключительно важное значение. Прежде всего, высокие требования предъявляются к его лексическому запасу: к свободному и точному употреблению на иностранном языке слов и военных терминов, непосредственно связанных с воинской службой, техникой, вооружением, поведением военнослужащих в условиях боевых и не только боевых действий и т. п. Причём точность понимания военной лексики имеет исключительно важное значение: при управлении боевыми средствами любая лексическая двусмысленность или недопонимание текста, например, технического описания оборудования, может привести к невыполнению боевой задачи и даже трагической ошибке, влекущей за собой гибель людей или невыполнение боевой задачи. В связи с этим обучение русскому языку в высших военных учебных заведениях характеризуется ярко выраженной профессиональной направленностью и осуществляется с целью формирования военно-профессиональной речевой и лингвистической компетенции у будущих офицеров. Заметим, что профессиональная компетентность и её составляющие являются основным направлением в развитии системы высшего образования в целом. Выпускник любого вуза, в том числе военной академии, должен обладать следующими качествами, требующими соответствующей языковой подготовки:

- легко и гибко ориентироваться в меняющихся жизненных ситуациях, приобретая необходимые знания и умело применяя их на практике;

- самостоятельно критически и творчески мыслить, быть способным осознать, где и каким образом приобретаемые языковые знания могут быть использованы;

- грамотно работать с информацией на иностранном языке;

- быть при необходимости коммуникабельным в самых разных ситуа-циях общения с представителями различных социальных и национальных групп;

- уметь работать в интернациональной команде, предотвращать конфликтные ситуации и выходить из них;

- стремиться к повышению собственного культурного и языкового уров-ня (Краснова, 2009: 4-5).

Наличие указанных качеств у будущих литовских офицеров необходимо - вполне возможно, что в ходе дальнейшей службы им доведётся контактировать с войсками, в значительной степени использующими военную технику и вооружение российского производства и, кроме того, именно русский язык 
может стать наиболее приемлемым и удобным средством профессионального общения.

Несмотря на то, что обучение русскому языку целесообразно начинать с освоения общеупотребительной лексики, обогащение словарного запаса кадетов специальной военной лексикой начинается практически с первых занятий по русскому языку и носит системный характер в направлении «от простого к сложному». Слово как основная единица языка, присутствующая на разных языковых ярусах, изучается комплексно, в единстве всех присущих ему сторон, начиная с фонетического образа слова и кончая функционированием словарной единицы в тексте. Таким образом, изучая русский язык в специальных целях, кадет осваивает единицы разных уровней языковой системы в их взаимодействии, постигая закономерности, действующие на каждом уровне.

Трудно переоценить важность лексической работы на занятии по РКИ. Постоянно находясь в центре внимания преподавателя, работа над лексикой естественно «вплетается во все виды учебной деятельности на занятии и включается в комплекс самых разных упражнений - фонетических, непосредственно лексических, грамматических, упражнений, направленных на развитие всех видов речевой деятельности, а также ведётся при работе со словарями и учебными текстами» (Краснова, 2009:5).

Лексическая компетенция военного специалиста предполагает наличие у говорящего (слушающего) знаний, умений и навыков в области как активного, так и пассивного словаря, то есть владение определенным запасом общеупотребительных слов, военных терминов, номинативных единиц с постоянной, утверждённой языковым коллективом связью между звуковым образом и его значением. Более того, кадет, обладающий лексической компетенцией, должен быть способен при необходимости проявить языковую догадку, а именно: определить значение неизвестного слова, опираясь на элементы его словообразовательной структуры, знание интернациональной лексики, информацию из контекста или исходя из речевой ситуации в целом. Поэтому в задачи преподавателя РКИ входит также развитие способности кадетов к языковой догадке. Не менее важным звеном профессиональной лексической компетентности является также желание и умение кадетов непрерывно пополнять свой словарный запас, работая со словарями, текстами, аудиовизуальными материалами военной тематики на русском языке, организовывая, таким образом, накопление запаса общеупотребительной и профессиональной лексики, а также их готовность применить полученные знания в реальной речевой ситуации, переводя таким образом накопленный пассивный лексический запас в активный.

Принимая во внимание крайне ограниченное количество учебного времени, отведённое на изучение второго иностранного языка в военной академии, а также зачастую на неоднородность самой учебной группы (имеем в виду разный уровень владения языком или, точнее, знакомства 
с выбранным кадетами для изучения языком), необходимо разрабатывать новые, более эффективные и отвечающие конкретным учебным условиям и современному состоянию методической науки методы и приёмы обучения. Думается, что в связи с вышесказанным на первый план выдвигаются следующие моменты:

- максимальная интенсификация использования аудиторного учебного времени за счёт привлечения новейших учебных технологий и так называемого метода активизации (МА);

- привлечение учебных и аутентичных аудиовизуальных материалов в процессе обучения, позволяющих сократить учебное время, отводимое для семантизации новых слов и для знакомства с формулами речевого этикета, а также воспроизводящих ситуации естественного языкового общения на изучаемом языке. Более того, является чрезвычайно важным тот факт, что аудиовизуальные материалы (документальные, художественные фильмы, репортажи и телевизионные передачи) обеспечивают знакомство кадетов с иной культурой и особенностями национального менталитета, а известно, что успешное овладение иностранным языком невозможно без создания у обучаемых необходимого спектра фоновых культурологических знаний о стране и народе - носителе данного языка. Добавим также, что использование аудиовизуальных материалов оживляет само занятие, обеспечивает слухо-зрительное восприятие речи и погружает кадетов в атмосферу привычного для них способа получения информации «с экрана»;

- ориентация на возможность использования компьютерных технологий в обучении языку, особенно при самостоятельной работе учащихся и при дистанционном обучении;

- индивидуальный подход к обучению - предложенные кадетам для изучения тексты и задания должны в идеале быть дифференцированы в соответствии с уровнем знаний каждого кадета. Постараемся прокомментировать данный тезис на конкретном примере. Допустим, при изучении темы «Боевое оружие и боеприпасы» кадетам предлагается прочитать текст об автомате Калашникова. Данный по тематике текст может быть представлен в двух вариантах: первый предназначается для обязательного чтения всеми учащимися, а второй, более сложный, в качестве дополнительного текста для чтения со словарём кадетам, чей уровень знаний позволяет справиться с усложнённой задачей;

Давайте сравним: 


\section{Текст 1. Автомат Калашникова в бою}

Михаил Тимофеевич Калашников - первый конструктор стрелкового автоматического оружия, который с 1942 года занимался его конструированием. В 1946 году он создал ряд автоматов, которые стали называться в честь него автоматами Калашникова.

Во время боя из автомата можно вести автоматический огонь и делать одиночные выстрелы. Чаще всего в бою солдаты ведут автоматический огонь, стреляют длинными очередями. Короткая очередь состочт из 3-5 выстрелов, длинная - из 8-10.

С помощью прицела из автомата Калашникова можно стрелять на расстоянии 1000 метров. Если вы стреляете метко, то можете уничтожить врагов на расстоянии 800 метров от вас. Хороший стрелок может попасть в самолёт, который летит на высоте 500 метров. Но особенно удобно вести огонь по цели, которая находится ближе 400 метров.

За одну минуту боеи может сделать до 40 выстрелов из автомата, а при стрельбе очередями - до 100.

(Текст составлен С. В. Красновой-Краснова, 2009: 11)

\section{Текст 2. Автомат Калашникова}

Наверное, не найдётся ни одного военнослужащего, который бы не слышал о русском автоматическом карабине - автомате Калашникова, который получил название по имени своего создателя. В народе автомат ласково называли просто «калашников».

Решение о начале конструкторских работ по созданию нового комплекса оружие-патрон было принято 15 июля 1943 года. Результатом чего стало принятие на вооружение в СССР автоматического карабина Калашникова.

Новый комплекс оружия под единый промежуточный патрон должен был включить в себя автомат (автоматический карабин), а также самозарядный (неавтоматический) магазинный карабин и ручной пулемёт. Любопытно, что этот разработанный образец не имел многих черт будущего АК, которые в наше время часто подвергаются критике.

Первый случай массового боевого применения АК на мировой арене произошёл 1 ноября 1956 года, в ходе подавления восстания в Венгрии. До этого момента автомат всячески скрывался от посторонних глаз: солдаты носили его в спеииальных скрадывающих очертания чехлах, а после стрельб все гильзы тщательно собирались. АК хорошо зарекомендовал себя в условиях городского боя.

По мере устаревания оружия стали всё в большей степени проявляться его недостатки, - как характерные для него в самом начале, так и выяв- 
ленные со временем в связи с изменением требований к стрелковому оружию и характера боевых действий.

В иелом и общем, хотя АК безусловно имеет многочисленные положительныл качества и долго ещё будет пригоден для вооружения вооружённых сил стран, в которых к нему привыкли, очевидна необходимость его замень более современными образцами, причём имеющими радикальные отличия в конструкции, которые позволили бы не повторять принципиальные недостатки устаревщей системьл.

В 2016 году на вооружение российской армии поступит автомат AK-12 концерна «Калашников», он придёт на смену устаревщему АК-74М. Об этом сообщил председатель коллегии Военно-промышленной комиссии РФ Олег Бочкарёв. Технические характеристики новой модели, разработанной в 2012 году, таковь:

Macca: 3,2 к2.

Длина: 1100 мм.

Длина ствола: 415 мм.

Патрон: $5,45 \times 39$ мм.

Принциипы работьл: отвод пороховых газов, длинный ход пориня, поворотный затвор.

Скорострельность: 650/1000 выстрелов/мин (автоматический режим / с отсечкой 3 патрона).

Начальная скорость пули: $900 \mathrm{~m} / \mathrm{c}$.

Прицельная дальность: $1100 \mathrm{M}$.

Вид боепитания: коробчатые 30- и 60-зарядный магазины, магазины барабанного типа на 95 патронов.

Прицел: съёмный комбинированный секторный, длина прицельной линии - 414 / 583 мм (открытый / диоптрический).

Данная модель автомата имеет ряд особенностей:

Во-первых, Калашников АК-12 облегчён за счёт легко снимаемого приклада, который может складываться в обе стороны. Боеи может производить все основные операции с автоматом одной рукой - переключать предохранитель, менять магазин и передёргивать затвор.

Во-вторых, Калашников АК-12 имеет удобные органы управления. Флажок предохранителя-переводчика огня изменён и продублирован с левой стороны, введена затворная задержка, кнопка которой также располагается с двух сторон.

В-третьих, в Калашникове АК-12 предусмотрена возможность стрельбы наствольными винтовочными гранатами. На оружие можно установить итатные подствольные гранатомёты ГП-25, ГП-30 или ГП-34.

(По материалам Википедии и интернета http://www.aif.ru/dontknows/file/1496072) 
- постоянная опора на языковую транспозицию, т.е. на языковой опыт родного и английского языка с целью позитивного переноса уже имеющихся речевых навыков. Транспозиция языковых навыков преимущественно осуществляется в области синтаксического построения предложений и других грамматических феноменов, а также при использовании интернациональных слов;

- повышение мотивации к изучению выбранного иностранного языка (в первую очередь за счёт привлечения учебных материалов, соответствующих возрасту, вкусам и профессиональным интересам кадетов и связанных с их будущей деятельностью или расширением их общего культурного диапазона знаний).

К сожалению, в рамках данной статьи мы не можем подробно остановиться на всех перечисленных моментах. Но хотелось бы детальнее охарактеризовать метод активизации в программе обучения русскому языку, тем более, что данный метод как нельзя лучше способствует усвоению большого количества новой лексики. Попробуем выделить принципы и характеристики данного метода, составляющие его незыблемую основу. Очень часто данный метод понимается как ввод в учебный процесс игровых и ролевых заданий, песен, разыгрывание набора определённых «жизненных» ситуаций и введение в ход занятия некоторых других «артистических» приёмов. Однако, нисколько не умаляя достоинств перечисленных приёмов, надо признать, что они практически не имеют отношения к МА, а относятся скорее к коммуникативному методу обучения иностранному языку.

Метод активизации - это научно обоснованная концепция обучения, целью которой является «обучение общению через общение» и которая предполагает ряд вполне определённых особенностей организации учебного процесса, базирующихся на конкретных психолого-педагогических принципах (Титкова, 2013: 33). Рассмотрим основные принципы МА в приложении к академическому курсу русского языка в Литовской военной академии.

1. Принцип личностно-ориентированного общения предполагает максимальное слияние общения и обучения и составляет кредо МА - обучающее общение. Сейчас ни у кого не вызывает сомнения, что личностное общение помогает установить в группе доверительные отношения и способствует наиболее продуктивному овладению изучаемого языка. Но для преподавателя РКИ, работающего по методу активизации, это инструмент планирования и построения занятия, способ общения с кадетами, который закладывается в сценарий каждого занятия. Методически грамотное общение требует от преподавателя определённого стиля работы, который предполагает:

- отбор или создание текстов, отвечающим личностным и профессиональным интересам кадетов, а также умение привязывать их к 
конкретной теме, представленной в учебнике;

- создание и формулировка заданий, предполагающих множественность ответов и, таким образом, стимулирующим общение (это варианты заданий, связанные с дискуссиями, обсуждениями, полемикой, т.е. задания, где кадету необходимо изложить свою точку зрения на проблему или по поводу прочитанного или услышанного);

- не оценивание ответа кадета, а корректировка с учётом грамматической и лексической правильности с акцентом на выражение отношения к содержанию его высказывания;

- отказ от фронтального опроса и умение передавать реплику (ответ, высказывание) одного кадета другим, там самым провоцируя их на собственные высказывания и реакции, что, в конечном счёте, стимулирует активность диалога в группе;

- умение «вплетать» в контекст вроде бы неформального личностного общения учебный материал (в частности - упражнения) и, наоборот, привнесение в сугубо учебный материал личностного содержания.

\section{2. Принцип ролевой организации учебного материала и процесса} обучения.

В данном случае хочется подчеркнуть, что ролевое общение - это не фрагмент занятия по РКИ, если речь идёт об интенсификации обучения. Специфика ролевого учебного общения состоит в том, что оно сохраняет все социально-психологические характеристики истинного, реального общения, которое всегда мотивировано, имеет вполне конкретные цели и предполагает наличие активных субъектов общения - реальных людей с их интересами, вкусами, настроением (Титкова, 2013: 36).

При построенном на принципе интенсификации занятии преподаватель:

- постоянно мотивирует и провоцирует речевые действия участников процесса коммуникации;

- даёт кадетам возможность проигрывать различные модели социального поведения;

- помогает им преодолевать языковой барьер, снимает чувство неловкости из-за допущенных языковых ошибок и в то же время предоставляет им возможность пробовать себя в новых ролях, примерять на себя новые качества и обстоятельства.

\section{3. Принцип концентрированности в организации учебного матери-} ала и учебного процесса связан, прежде всего, с объёмом изучаемого материала и его распределением в курсе русского языка. Данный принцип предполагает взаимодействие и взаимозависимость достаточно большого объёма изучаемого материала и способствует активизации учебно-познавательной деятельности. Такая взаимозависимость носит двусторонний характер: акти- 
визация учебной деятельности и повышение темпа занятия, с одной стороны, создаёт почву для успешного усвоения повышенных объёмов концентрированной учебной информации, а с другой стороны, насыщенность новой информацией учебного материала активизирует познавательную деятельность и способность кадетов к усвоению нового. Как утверждает С. Титкова, учащийся перестраивается на более активный режим работы, который способствует максимальным проявлениям его творческих способностей, в частности способности запоминать большие объёмы информации без предварительного заучивания (Титкова, 2013: 38). Надо отметить, что в данном случае очень важно правильно распределить учебный материал, предназначенный для аудиторной и самостоятельной работы кадетов. Наш опыт показывает, что домашние задания должны состоять из заданий, на 80\% включающих уже известный кадетам материал и выполнять функцию повторения и обобщения пройденного, закрепления новой изученной на занятии лексики и грамматики. Также обязательны творческие домашние задания, направленные на поиск в интернете информации, связанной с их будущей профессиональной деятельностью.

Существует ряд способов активизации познавательной деятельности учащихся. В качестве примера можно упомянуть такой методический приём как опережающее программу введение сложных речевых конструкций, например, - целевых с союзом чтобы или условных с союзом если без их грамматического анализа для того, чтобы дать возможность кадетам пользоваться речевыми моделями на раннем этапе обучения. Другой способ активизации познавательной деятельности связан с предваряющим характером домашнего задания, то есть когда кадет сначала знакомится с новым материалом (чаще грамматическим) самостоятельно, и только потом, на занятии, этот материал (в случае необходимости) объясняет преподаватель. Добавим, что в учебнике есть грамматический комментарий, с которым кадеты вполне способны разобраться сами. Другими словами, выстраивается следующая «цепочка» подачи материала: самостоятельный анализ теории (грамматического материала) --- выполнение домашнего задания --- объяснение или комментарий преподавателя. Мы придерживаемся точки зрения, что такая организация учебного процесса стимулирует активное, осознанное участие кадета в занятии независимо от того, смог ли он самостоятельно разобраться с новым языковым материалом, или, возможно, понял тему недостаточно хорошо или не понял вовсе.

В заключение подчеркнём, что использование метода МА на занятиях РКИ положительно сказывается не только на работоспособности, но и на поддержании «интеллектуального тонуса» кадетов, что необходимо для усвоения больших объёмов лексического и грамматического материала. Однако не стоит забывать о том, что высокая концентрация учебного материала и активная учебная деятельность могут спровоцировать психологическое напряжение у кадетов, особенно у тех, чей уровень знаний слабее среднего уровня группы. Поэтому метод МА включает понятие коммуникативной связанности матери- 
ала занятия, которая стимулирует взаимодействие учащихся и облегчает усвоение большого объёма информации. Благодаря коммуникативной связанности создаётся лёгкость в восприятии новых учебных текстов, снимается монотонность и поддерживается мотивация при выполнении заданий лексико-грамматического характера. Преподаватель может исполнять роль «дирижёра», предлагая более слабым учащимся менее трудные задачи и позволяя им «накопить» необходимый потенциал знаний для выполнения более трудных заданий. Такое занятие оживляется вводом в учебный процесс видеосюжетов, связанных с темой занятия и иллюстрирующих употребление усваиваемой лексики и речевых образцов в реальной ситуации общения на русском языке. Просмотр видеовставок повышает мотивацию кадетов к общению и нивелирует разницу в их языковой подготовке. В плане методики, сюжетная линия занятия, основанного на принципе коммуникативной связанности, предполагает наполнение коммуникативным смыслом каждого выполняемого кадетами задания и выстраивания между заданиями смысловых связей. Все задания как бы объединяются единой макроситуацией, которая реализуется в связанных по смыслу и дополняющих друг друга микроситуациях, в результате чего обеспечивается спиральное повторение и закрепление лексического и грамматического материала с привлечением нового аспекта по заданной теме.

\section{Выводы}

Таким образом, мы приходим к выводу, что успешное овладение вторым иностранным языком во многом зависит от оптимального сочетания методов и приёмов обучения. Не исключая важности использования традиционных методов обучения, нужно заметить, что на смену им или, точнее, в дополнение к ним приходят новые способы обучения, предполагающие использование всего арсенала современных технологий, начиная с применения возможностей аудиовизуальных средств обучения и кончая разработанными методистами компьютерными программами для аудиторного и дистанционного обучения языку. Принимая во внимание цели и специфику обучения иностранному языку в военных вузах, можно утверждать, что важным и определяющим фактором обучения становится создание у кадетов необходимого словарного запаса на русском языке и минимума грамматических навыков для продуцирования русской речи. Кроме того, в обучении второму иностранному языку при крайне ограниченном учебном аудиторном времени исключительную роль играет интенсификация самого учебного процесса и в этой связи метод активизации становится ведущим методом на занятиях по РКИ. Учитывая разный уровень владения выбранным для изучения языком кадетами одной группы, преподаватель должен использовать дифференцированный подход к обучению. При изучении второго иностранного языка первостепенную важность приобретает изучение профессиональной лексики и военной терминологии, которое долж- 
но осуществляться параллельно с вводом общеупотребительной лексики на всех этапах обучения.

\section{Литература}

1. Краснова, Светлана В. (2009) Дружно за мир стоять - войне не бывать. Обучение курсантов-инофонов военной лексике на подготовительном отделении. Русский язык за рубежом, N3.C.4 - 22.

2. Титкова, Светлана И. (2013) Специфика реализации принципов метода активизации в программе обучения русскому языку студентов Летней школы Миддлбери. Русский язык за рубежом, N1. С. 33 - 42.

3. Шантурова, Галина А. (2013) Современные методические технологии на практических занятиях по РКИ. N1. С. 26 - 32. 


\title{
MODERN TECHNOLOGIES AND METHODS OF TEACHING IN PRACTICAL COURSE OF RUSSIAN (AS A FOREIGN LANGUAGE) AT THE GENERAL JONAS ŽEMAITIS MILITARY ACADEMY OF LITHUANIA
}

\author{
Assoc. Prof. Dr. Jelena Kazimianec \\ The General Jonas Žemaitis Military Academy of Lithuania
}

\section{Summary}

The article analyzes the tasks and specific methods of teaching Russian as the second foreign language at The General Jonas Žemaitis Military Academy of Lithuania. The article defines the set of qualities that make up a professional speaking and linguistic competence of the graduates of the higher military educational institution.

The author emphasizes the importance for the trainees to have a sufficient vocabulary of the foreign (Russian) language, which should be in common with the vocabulary of native speakers, who are the representatives of different language and cultural groups. The paper indicates the feasibility of entering special military vocabulary and terminology from the earliest stages of learning a foreign language. The article also proves the necessity for intensification of educational process by the use of new methods and technologies of foreign language teaching. The author supposes that the best way is to produce a well-thought-out combination of different methods of teaching during a lesson.

The method of activation is considered as one of the main methods of teaching Russian at the Military Academy of Lithuania. The author concludes that a successful mastery of the second foreign language learning to a great degree depends on an optimal combination of methods and techniques of teaching. While not excluding the importance of the use of traditional teaching methods, the author points to the need of using new ways of learning, involving the use of entire arsenal of modern technology starting with the use of audiovisual training materials and ending with computer programs for classroom and distance language learning developed by teachers and methodologists.

A teacher should be prepared to use a differentiated approach to teaching a foreign language chosen by cadets for learning because their level of language knowledge can be, and mostly is, different in a group. In addition, professional vocabulary and military terminology learning becomes extremely important for the cadets who learn Russian as the second foreign language. That is why this language material must be carried out and introduced into the practice in parallel with the introduction of general everyday vocabulary at all stages of training. 


\section{AUTORIAUS LYDRAŠTIS}

Autoriaus vardas, pavardè: Jelena Kazimianec

Mokslo laipsnis ir vardas: humanitarinių mokslų daktarè, docentė

Darbo vieta ir pareigos: Generolo Jono Žemaičio Lietuvos karo akademijos docenté; Lietuvos edukologijos universiteto docentè

Autoriaus mokslinių interesų sritys: dabartinė rusų kalba, rusų kalbos gramatika, lingvokultūrologija, svetimųjų kalbų dèstymo didaktika, sociolingvistika, komparatyvistinè lingvistika

Telefonas ir el. pašto adresas: 868759 272; jelena.kazimianec@lka.lt

\section{AUTHOR'S COVER LETTER}

Author's name and surname: Jelena Kazimianec

Academic degree and name: Associate Professor, Doctor

Workplace and position: The General Jonas Žemaitis Military Academy of Lithuania, Department of Foreign Languages, Associate Professor; Lithuanian University of Educational Sciences, Faculty of Philology, Associate Professor, Doctor

Author's research interests: modern Russian, Russian grammar, comparative linguistics, foreign language teaching methods, social linguistics, lingua-culturology

Telephone and e-mail address: +370 68759 272; jelena.kazimianec@lka.lt 